\title{
GEOGEBRA: RECURSO VISUAL E CINESTÉSICO NO ENSINO DE FUNÇÕES
}

\author{
W. G. FEITOZA ${ }^{1}$, E. J. R. MEDEIROS ${ }^{2}$, S. R. R. MEDEIROS ${ }^{3}$, R. N. MEDEIROS JR ${ }^{4}$, E. G. LOURENÇO ${ }^{5}$
}

Colégio Militar de Recife ${ }^{1}$, Instituto Federal de Educação, Ciência e Tecnologia do Rio Grande de Norte ${ }^{1-5}$

ORCID ID: https://orcid.org/0000-0001-9731-5794 ${ }^{1}$

weddington.feitoza@academico.ifrn.edu.br ${ }^{1}$

Submetido 14/04/2020 - Aceito 06/08/2020

DOI: 10.15628/holos.2020.9911

\section{RESUMO}

Este artigo tem como objetivo apresentar o Software matemático GeoGebra como uma ferramenta tecnológica capaz de propiciar ao aluno de matemática, especialmente no estudo das funções afim e quadrática, a possibilidade de desenvolver uma aprendizagem mais dinâmica e interativa, favorecendo, sobretudo, os alunos que apresentam maior facilidade de aprendizagem pela utilização dos canais visuais e cinestésicos, como será observado ao longo deste trabalho investigativo, que submeteu um grupo heterogêneo de 30 alunos da rede pública federal, do último ano do ensino fundamental, a aulas sobre funções afim e quadrática, com e sem o apoio do GeoGebra. O Software também se apresentou como uma opção de ensino moderno e conectado, uma vez que opera em múltiplas plataformas, como nos smartphones, tablets e notebooks, inclusive na versão online.

PALAVRAS-CHAVE: Software, Ensino de Matemática, Ciência, Tecnologia.

\section{GEOGEBRA: VISUAL AND KINESTHETIC RESOURCE IN THE TEACHING OF FUNCTIONS}

\begin{abstract}
This article aims to present the GeoGebra Mathematical Software as a technology tool capable of providing the student of mathematics, especially in the study of affine and quadratic functions, the possibility of developing a more dynamic and interactive learning, favoring, especially, those students who present greater ease of learning in the use of the visual and kinesthetic channels, as will be observed throughout this investigative work,
\end{abstract}

which submitted a heterogeneous group of 30 students from the federal public network, in the last year of elementary education, to classes on affine and quadratic functions, without and with the support of GeoGebra. The Software also presented itself as an option in modern and connected teaching since it operates in multiple platforms, such in the smartphones, tablets and notebooks, including in the online version.

KEYWORDS: Software, Mathematics Teaching, Science, Technology. 


\section{INTRODUÇÃO}

Nas rotinas da sala de aula, tem-se percebido um descompasso entre as metodologias ultrapassadas de ensino, aplicadas na maioria das instituições de ensino brasileiras, e o ritmo acelerado e inquieto de absorção do conhecimento empregado pela geração que agora ocupa as cadeiras escolares, especialmente nos últimos anos do ensino fundamental e no ensino médio. Em virtude da inclusão digital, a "[...] sociedade está caminhando para ser uma sociedade que aprende de novas maneiras, por novos caminhos, com novos participantes (atores), de forma contínua" (Moran, 2007, p.11).

De acordo com Moran (2007), escolas desconectadas são, atualmente, consideradas escolas incompletas, e alunos sem acesso às redes digitais são alunos excluídos de parte importante da aprendizagem atual.

No ensino de disciplinas exatas como física e matemática tem-se buscado ferramentas para melhorar o processo ensino-aprendizagem em sala de aula, com foco principal na criação de ambientes de aprendizagem onde a participação do professor seja de mediador das atividades. "Experiências escolares com o computador têm mostrado que seu emprego pode levar ao estabelecimento de uma nova relação professor-aluno, marcada por uma maior proximidade, interação e colaboração" (Rodrigues, 2014, p.18).

É importante que os alunos tenham a possibilidade de escolher o método de aprendizagem que melhor lhes convier, uma vez que, cada aluno possui um Sistema Representacional Preferencial diferente. Indivíduos diferentes precisam de metodologias distintas. Uma das grandes vantagens das novas tecnologias é a possibilidade da individualização do ensino e do processo ensino sem fronteiras, pois algumas tecnologias permitem que o aluno tenha acesso à informação em qualquer lugar e hora, e o professor não necessariamente precisa estar na presença do aluno para realizar intervenções.

Segundo Antunes (2007), existem diferentes processos de aprendizagem, que ocorrem de modo distinto em cada indivíduo, e dos quais o professor precisa se apropriar. Este estudo busca refletir sobre a possibilidade de utilização do software GeoGebra em sala de aula, na função de simulador, como uma ferramenta facilitadora no ensino de funções do primeiro e do segundo grau na disciplina de matemática, em turmas do Ensino Fundamental, assim como, um método com possibilidades de simular situações no ambiente extra classe, facilitando a visualização comportamental de uma função e, por consequência, a aprendizagem do conteúdo.

A pesquisa foi desenvolvida durante as aulas de matemática em uma turma de 9 o ano do Ensino Fundamental de um Colégio da rede pública federal, na cidade de Recife-PE. O despertar inicial pela temática se deu em virtude da heterogeneidade dos integrantes do Ensino Fundamental na referida instituição, resultante das formas de ingresso. Alguns dos alunos, por serem submetidos a um processo de seleção muito rigoroso, apresentam elevado nível de conhecimento em matemática básica, o que não ocorre com a outra parcela. Os estudantes são naturais dos mais diversos locais do Brasil, desde comunidades isoladas no interior da Amazônia, até grandes centros urbanos, como Brasília-DF. 
Diante de tamanha disparidade no acesso ao ensino básico, dificuldades na comunicação apresentadas por alguns alunos, e a deficiência em matemática básica dos alunos não concursados, surgiu a necessidade de buscar um modelo de ensino que contemplasse a individualidade e o ensino de forma assíncrono.

Ao tentar equacionar o problema supracitado, inicialmente pelo uso de redes sociais, canais de vídeos e plataformas educacionais gratuitas, verificou-se que os alunos com maior dificuldade, e menor interação na disciplina de matemática, passaram a apresentar maior participação nas aulas e melhores resultados nas avaliações.

Como resposta ao resultado positivo apresentado anteriormente, cresceu o interesse em buscar ferramentas e formas de melhor entender e atender a individualidade dos alunos daquela turma, bem como, o potencial facilitador das novas ferramentas tecnológicas disponíveis, sobretudo, aquelas voltadas para a educação matemática.

Ao longo dos últimos anos, muito se discute sobre a utilização das Tecnologias de Informação e Comunicação - TIC nas atividades pedagógicas, desde a formação dos professores para o trabalho com essas ferramentas, até a proibição do uso pelos alunos no ambiente escolar. A questão norteadora é que a nova geração de crianças e jovens do século 21 já nasceu em uma sociedade tecnológica e conectada, e, por essa razão, as tecnologias móveis como tablets e celulares começam a ganhar espaço nos processos de ensino e aprendizagem. De acordo com a pesquisa TIC educação 2015, realizada nas escolas públicas e privadas de áreas urbanas pelo Comitê Gestor da Internet no Brasil, 73\% dos professores já incorporam o computador e a internet como ferramenta pedagógica, seja para trabalhos em grupos ou para a realização de exercícios. 0 celular é utilizado para atividades por $39 \%$ dos professores.

Segundo o mesmo Comitê Gestor da Internet no Brasil (2016), em sua busca por ferramentas tecnológicas que pudessem contribuir com o processo de aprendizagem, apresentou - GeoGebra, um software matemático que une Geometria, Álgebra e Cálculo, por meio de duas janelas de visualização, a janela geométrica (Figura 1) e a janela algébrica (Figura 2). Desse modo, cada objeto construído na janela geométrica tem sua representação mostrada na janela algébrica, e cada alteração realizada em uma das janelas produz efeito instantâneo na outra. A dinâmica do GeoGebra privilegia sobremaneira a possibilidade de o aluno exercitar simultaneamente os canais Auditivo, Visual e Cinestésico, uma vez que a informação transmitida pelo professor pode ser ouvida, testada e visualizada pelo aluno na tela do aplicativo. 


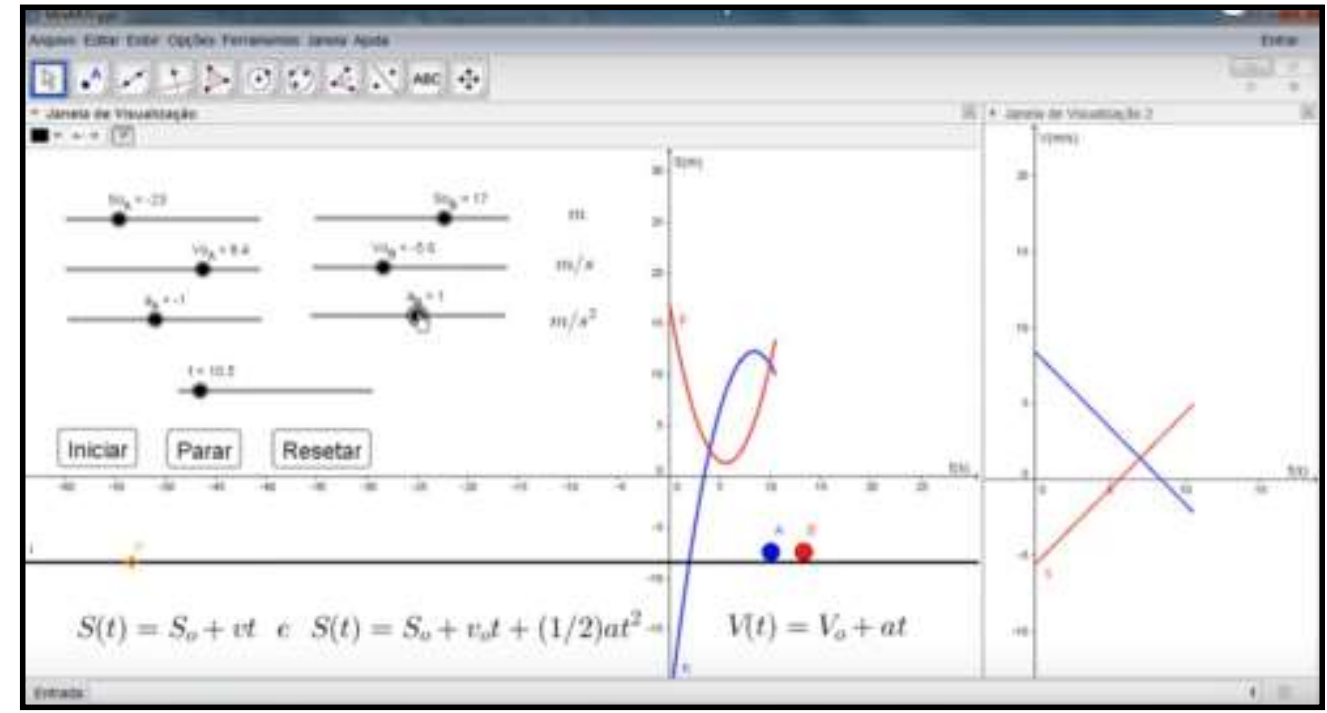

Figura 1 - Janela de Visualização

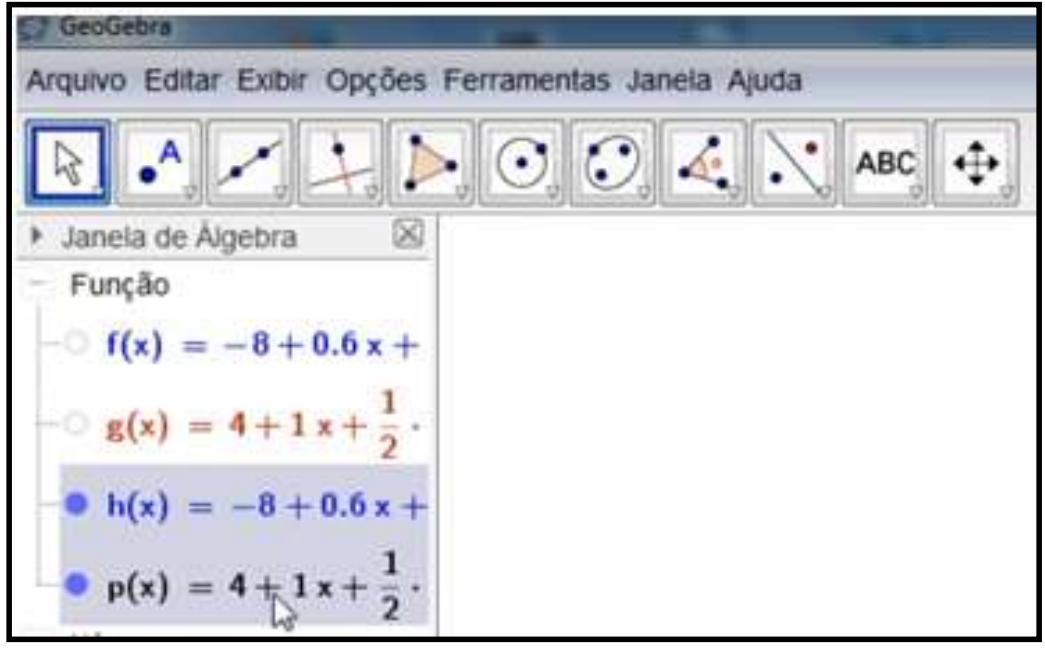

Figura 2 - Janela de Álgebra

Considerando que o público alvo do estudo foi uma turma do $9^{\circ}$ ano no Ensino Fundamental, que está iniciando o contato com um conceito tão importante na área das ciências exatas - o conteúdo de funções - e, em virtude de relatos do professor de física da mesma turma, a respeito da dificuldade que os alunos estavam apresentando em entender o comportamento das funções afim e quadrática, resolveu-se estudar as consequências da utilização do GeoGebra no ensino dessas funções, associando a uma aplicação direta nos Movimentos Retilíneos Uniformes (MRU) e Movimentos Retilíneos Uniformemente Variados (MRUV), ambos, conteúdos da disciplina de Física.

O objetivo principal do estudo foi verificar, durante o ensino das funções afim e quadrática, o impacto do GeoGebra nesse universo de alunos tão heterogêneo e as consequências na compreensão dos assuntos de MRU e MRUV, sabendo que o entendimento da cinemática passa pela correta aplicação e compreensão dos conceitos de função. 


\section{FUNDAMENTAÇÃO TEÓRICA}

De acordo com Lopes e Tosina (2011), na formação de um aluno do século atual, precisam prevalecer os aspectos essenciais nos projetos educativos, em torno do desenvolvimento de aptidões e habilidades básicas, especificas e tecnológicas, além de incluir o conceito de aprender a aprender. Em virtude disso, resulta a necessidade de reconhecimento das novas tecnologias como ferramentas que ajudem a potencializar os contextos educativos, através da criação de novos espaços e oportunidades para o acesso e desenvolvimento de informação e do conhecimento.

Montgomery (1995) afirma ser possível verificar uma diferenciação no resultado da aprendizagem entre dois grupos de alunos, quando um deles é submetido a um ensino com emprego de tecnologias digitais e o outro é submetido ao ensino tradicional. O emprego de tecnologias digitais na educação permite que o processo de aprendizagem ocorra de forma assíncrona e individualizada, atendendo de forma considerável as particularidades do estilo de aprendizagem de cada aluno.

Buscando fugir da maneira tradicional de se trabalhar os currículos escolares, baseados na multidisciplinaridade, que corresponde à estrutura tradicional de currículo fragmentado em várias disciplinas desenvolvidas isoladamente, este trabalho baseou-se na interdisciplinaridade, estabelecendo relações entre as disciplinas de Matemática e Física.

Antes de tudo, é preciso conceituar as diferenças entre multidisciplinaridade e interdisciplinaridade. Segundo Almeida Filho (1997), na multidisciplinaridade, os alunos estudam as disciplinas curriculares próximas, porém não em conjunto. Em relação à interdisciplinaridade e de acordo com as Diretrizes Nacionais Curriculares (1999, p. 133):

A interdisciplinaridade não dilui as disciplinas, ao contrário, mantém sua individualidade. Porém integra as disciplinas a partir da compreensão das múltiplas causas ou fatores que intervêm sobre a realidade e trabalha todas as linguagens necessárias para a constituição de conhecimentos, comunicação e negociação de significados e registro sistemático dos resultados.

Em outras palavras, a interdisciplinaridade estabelece relações entre duas ou mais disciplinas ou ramos de conhecimento, ou o que é comum a duas ou mais disciplinas.

\subsection{Estilos de aprendizagem}

Conforme apresentado por Alonso e Gallego (2002 apud KEEFE, 1988), os estilos de aprendizagem são características cognitivas, emocionais e fisiológicas que servem como indicadores, relativamente estáveis, de como os estudantes percebem e respondem a interações nos ambientes de aprendizagem.

Na opinião de López e Velásques (2008), cada aluno responde a um modelo individual e predominante de aprendizagem que the permite relacionar-se com o ambiente e que envolve aspectos cognitivos referentes à sua personalidade, ou seja, ao falar sobre o modo de aprender, dois aspectos importantes devem ser considerados: a percepção e o processamento da informação. 
De acordo com Mojica (2001), entre outras características de estilos de aprendizagem pode-se citar:

- Aprendizagem é um processo interativo. É o produto de uma atividade em um ambiente específico, e que mostra variações entre padrões, estilo e qualidade.

- Estilos influenciam o modo como os alunos aprendem, como os professores ensinam e como ambos interagem.

- Os alunos aprendem diferentemente uns dos outros, com pontos fortes, limitações e preferências na maneira de receber e processar informações.

- O estilo de aprendizagem é tanto uma característica do aluno quanto uma estratégia instrucional.

- Os educadores devem ser capazes de responder às necessidades de seus alunos, planejando e criando um ambiente educacional que promova e apoie as características únicas de seus estilos de aprendizagem.

\subsection{GeoGebra}

O GeoGebra é um software gratuito criado por Markus Hohenwarter, da Universidade de Salzburg, que iniciou o projeto no ano de 2001. Foi desenvolvido com o intuito de ser uma ferramenta educacional que auxilia, de forma dinâmica, no ensino da Matemática através de funcionalidades que envolvem o uso de geometria, álgebra, cálculo, tabelas, estatística, dentre outras. (FERRI; SCHIMIGUEL; CALEJON, 2013)

Os principais motivos para a utilização do GeoGebra são o fato de ser um software livre, uma interface de fácil manuseio e sua mediação no processo de investigação para resolução de problemas, proporcionando um estudo dinâmico. Além disso, ele foi escrito em linguagem Java, o que possibilita seu funcionamento em qualquer plataforma, principalmente nas plataformas móveis. O software não está limitado apenas ao estudo de figuras geométricas, pois ainda possibilita a construção de gráficos dos mais diferentes tipos de funções.

A interface do GeoGebra é composta por várias ferramentas, que possibilitam a construção de pontos, segmentos, retas e funções, que podem ser manipulados e investigados em tempo real, além de interligar a representação gráfica com a sua respectiva forma algébrica. $O$ software ainda possibilita a construção de uma ou mais figuras geométricas ou gráficos em uma mesma tela, proporcionando uma maior interação entre elas, o que resulta na ampliação do campo de observação e contribui para a construção e análise de conceitos.

A principal função do software GeoGebra é aproximar as diferentes formas de representar um determinado problema matemático, buscando maximizar não só a visualização estática dos dados, como também os eventuais fenômenos decorrentes do processo de manipulação das variáveis. 
Para Lévy (1993), o GeoGebra tem a capacidade de aumentar o componente visual do problema matemático, contribuindo para o entendimento, especialmente para os alunos que possuem o visual como sistema de aprendizagem predominante.

Segundo Borba (2010), se a educação está mudando devido à introdução de novas tecnologias, é coerente prever que a matemática também passará por algumas mudanças.

Pode-se destacar algumas das peculiaridades do processo visual, proporcionadas pela aplicação das tecnologias na educação matemática:

- A visualização é um meio alternativo de acesso ao conhecimento matemático.

- A compreensão de conceitos matemáticos requer diversas representações e as representações visuais podem transformar o seu entendimento.

- A visualização faz parte da atividade matemática, e é uma maneira de resolver problemas.

\subsection{Conceitos básicos: Funções afim e quadrática}

Ao definir as funções afim e quadrática, admite-se que já exista a familiaridade com os conceitos de funções e suas respectivas propriedades.

\subsubsection{Função afim}

Sendo $R$ o conjunto dos números Reais, uma função $f: R \rightarrow R$, chama-se afim quando existem constantes reais $a$ e $b$, tais que $f(x)=a x+b$, para todo $x \in R$. (Lima, 2008, p. 87)

São exemplos:

- $f(x)=2 x+1 \quad(a=2, b=1)$

- $f(x)=-x+4 \quad(a=-1, b=4)$

Como é possível observar, na função afim tem-se dois números reais denominados de coeficientes, sendo o primeiro denominado como coeficiente angular e o segundo como coeficiente linear. O coeficiente linear é "a ordenada do ponto onde a reta intercepta o eixo y (abscissa nula) é sempre b." (Dante, 2008, p. 61).

Já o coeficiente angular " $a$ " corresponde à tangente do ângulo que a reta forma com o eixo $x$, ou seja, quando o valor de " $a$ " vai aumentando a reta foge a posição horizontal. Esses coeficientes estão sempre sujeitos a alterações, assumindo assim diferentes valores no conjunto dos números Reais, o que acaba apresentando alguns casos particulares importantes no estudo da função afim.

Também é válido ressaltar que, segundo Lima (2008), uma função real $f: X \rightarrow R$, com $X \subset$ $A$, chama-se crescente quando $x_{1}<x_{2} \Rightarrow f\left(x_{1}\right)<f\left(x_{2}\right)$ e decrescente quando $x_{1}<x_{2} \Rightarrow$ $f\left(x_{1}\right)>f\left(x_{2}\right)$. Especificamente para função a fim, isso ocorre quando o coeficiente angular "a" é positivo (função crescente) ou negativo (função decrescente).

O gráfico de uma função afim será representado sempre por uma reta, determinada pela ligação dos pontos das coordenadas definidas no plano cartesiano. "Para construir o gráfico de 
uma função afim, atribuímos valores do domínio à variável e calculamos as respectivas imagens." (Dante, 2008, p. 57).

A Figura 3 apresenta o exemplo da construção do gráfico da função $f(x)=2 x+1$ :

\begin{tabular}{|c|c|}
\hline$x$ & $y$ \\
\hline-2 & -3 \\
\hline-1 & -1 \\
\hline 0 & 1 \\
\hline 1 & 3 \\
\hline 2 & 5 \\
\hline 3 & 7 \\
\hline
\end{tabular}

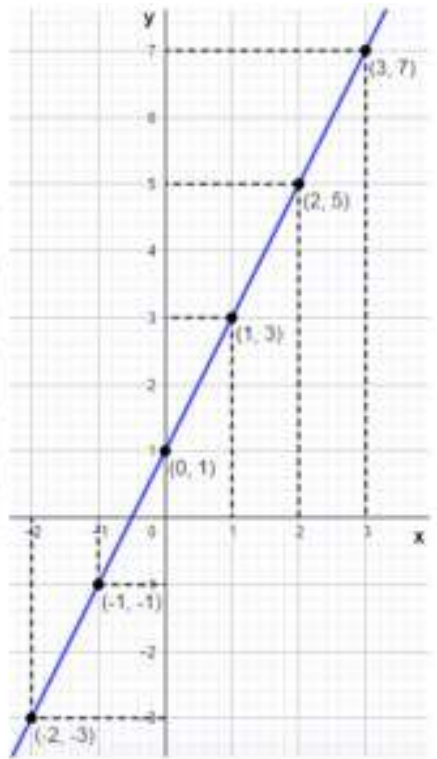

Figura 3 - Construção do gráfico de uma função afim

\subsubsection{Função quadrática}

Chama-se de função quadrática, a função $f: R \rightarrow R$, que associa cada $x \in R$ ao valor $f(x)=a x^{2}+b x+c \in R$, com $a, b$ e $c$ sendo números reais e $a \neq 0$ (Soares, 2013, p. 13).

São exemplos:

- $f(x)=3 x^{2}-4 x+1 \quad(a=3, b=-4, \mathrm{c}=1)$

- $f(x)=x^{2}-1 \quad(a=1, b=0, \mathrm{c}=-1)$

Como é possível observar, na função quadrática tem-se três números reais $(a, b$ e $c)$ denominados de coeficientes. No gráfico, eles vão determinar a concavidade da parábola (coeficiente $a$ ); a inclinação (crescente, decrescente ou constante) da reta tangente à parábola no ponto $(0, c)$ (coeficiente $b$ ); e o ponto de intersecção com o eixo $y$ (coeficiente $c$ ).

O fato de o coeficiente " $a$ " ser diferente de zero garante que não se considere a função afim como um caso particular da função quadrática.

Conforme mencionado anteriormente, o gráfico de uma função quadrática, $y=a x^{2}+$ $b x+c$, com $a \neq 0$, é uma curva chamada parábola. A Figura 4 apresenta o exemplo do gráfico da função $y=x^{2}+x$. 


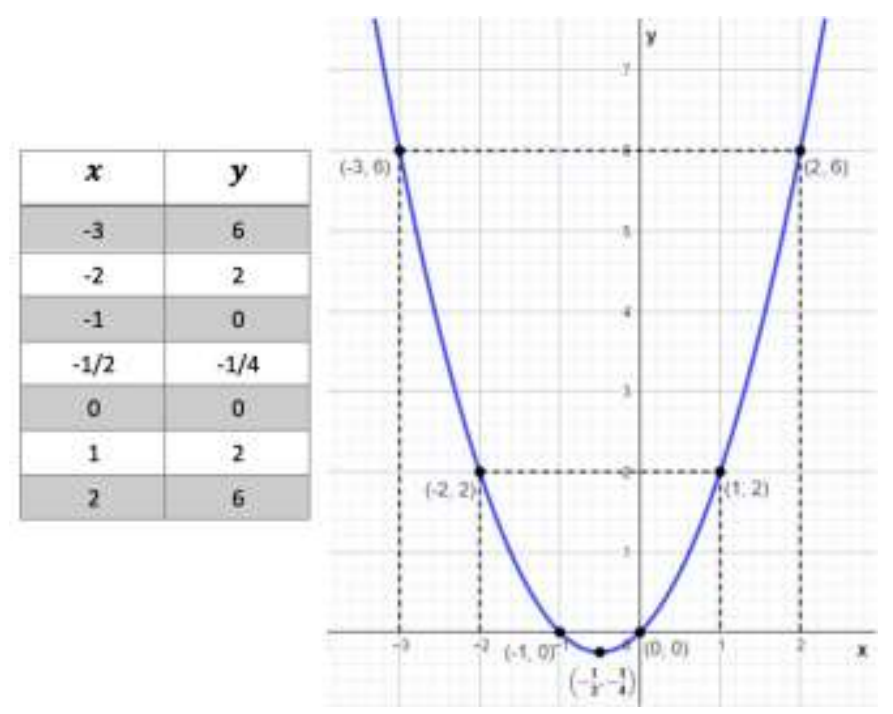

Figura 4 - Gráfico de uma função quadrática

\section{METODOLOGIA}

Trata-se de um estudo de caso realizado através da coleta de dados e leituras bibliográficas, desenvolvido durante as aulas de Matemática numa turma de 9o ano do Ensino Fundamental, com 30 alunos de um colégio da rede pública federal, na cidade de Recife/PE. O intuito foi verificar possibilidades que melhor atendam a uma turma com perfis diversos, que, inclusive, é a realidade da maioria das salas de aula no Brasil. Esta, em particular, por um lado possui alunos com elevado nível de conhecimento em matemática básica - além de facilidade na comunicação e aprendizagem - e de outro, alunos com extrema dificuldade, alguns até mesmo com necessidades educacionais especiais.

O conteúdo escolhido para o estudo foi o de funções, particularmente função afim e função quadrática, em razão de relatos do professor de Física da mesma turma, que estava iniciando o estudo de movimentos de objetos, e enfrentando enormes dificuldades de alguns alunos na compreensão e representação do comportamento e alterações dessas funções, especialmente durante a análise de Movimento Retilíneo Uniforme e Uniformemente Variado.

O GeoGebra surgiu como uma opção de ferramenta auxiliar na representação gráfica do comportamento das funções afim e quadrática durante a alteração de seus parâmetros, contudo, para estudar o impacto da utilização do software, a etapa inicial foi utilizada como modelo de comparação, com a introdução do assunto de maneira direta e tradicional, e mensuração imediata da aprendizagem (Avaliação Imediata). Em seguida, o conteúdo foi reapresentado, porém, desta vez, com o auxílio do GeoGebra. A mesma avaliação foi novamente aplicada e os resultados foram comparados. Também foi conduzido um Teste Neurolinguístico, com o objetivo de analisar o Sistema Representacional Preferencial de cada aluno.

Ao final, ainda se utilizou um aplicativo construído no GeoGebra para discutir o comportamento gráfico do deslocamento de dois objetos, levando em consideração a alteração 
de parâmetros como velocidade inicial, espaço inicial, aceleração e tempo, de modo a atingir o outro objetivo, de promover a aplicação do software como facilitador no ensino do MRU e MRUV.

\subsection{Aula tradicional}

No decorrer de duas aulas de 45 minutos, totalizando 90 minutos, foram apresentados apenas conceitos fundamentais e a representação gráfica de situações gerais, sem abordar casos particulares. Nesta etapa, foram utilizados apenas quadro branco e pincel, e, como técnicas de ensino, foram utilizadas a aula expositiva e avaliação imediata.

\subsection{Aula com auxílio do GeoGebra}

No decorrer de outras duas aulas de 45 minutos, os mesmos conceitos apresentados através da aula tradicional foram novamente abordados, porém, dessa vez, com o auxílio visual e prático do GeoGebra. Enquanto os conceitos eram apresentados, os alunos puderam acompanhar toda a construção do gráfico, desde a escrita da função até a localização dos pontos no plano cartesiano, conforme apresentado na Figura 5.

Nesse momento, a aula ocorreu no laboratório de informática, onde os computadores e uma tela de projeção foram utilizados como meios auxiliares, todos com acesso à internet. Após a abordagem teórica do assunto, os alunos puderam vivenciar as experiências com o GeoGebra através dos endereços eletrônicos disponibilizados em cada máquina, praticando, criando situações e discutindo com os colegas o comportamento da função afim diante de cada alteração realizada nos coeficientes " $a$ " e " $b$ ", e o comportamento da curva da função quadrática diante de cada alteração realizada nos coeficientes " $a$ ", " $b$ " e " $c$ ".

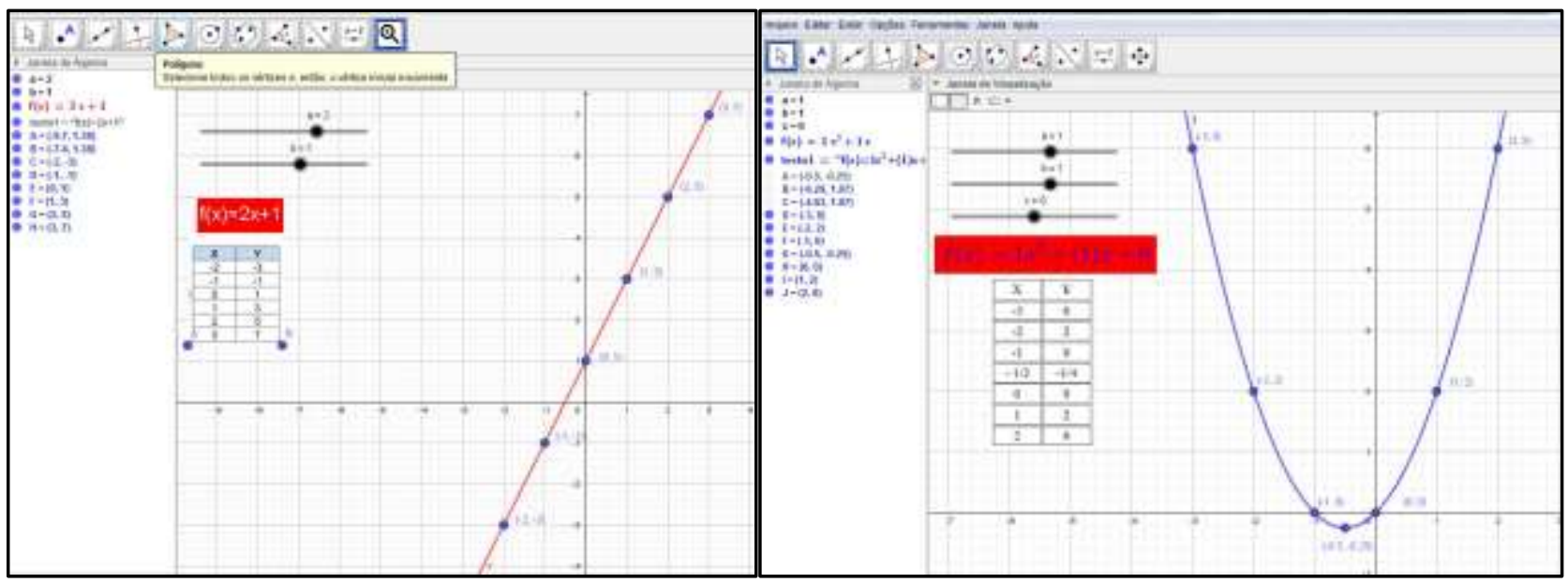

Figura 5 - Gráficos da função afim (à esquerda) e da função quadrática (à direita) construídos no GeoGebra.

No mesmo aplicativo produzido para as aulas de funções (Figura 6), através de um comando denominado controle deslizante, foi possível realizar animação simultânea da representação gráfica e simular o deslocamento de dois objetos em uma pista. Matematicamente falando, o GeoGebra possibilitaria que o aluno visualizasse, ao mesmo tempo, a alteração algébrica e a alteração gráfica da função, além de uma aplicabilidade direta do assunto de funções. 


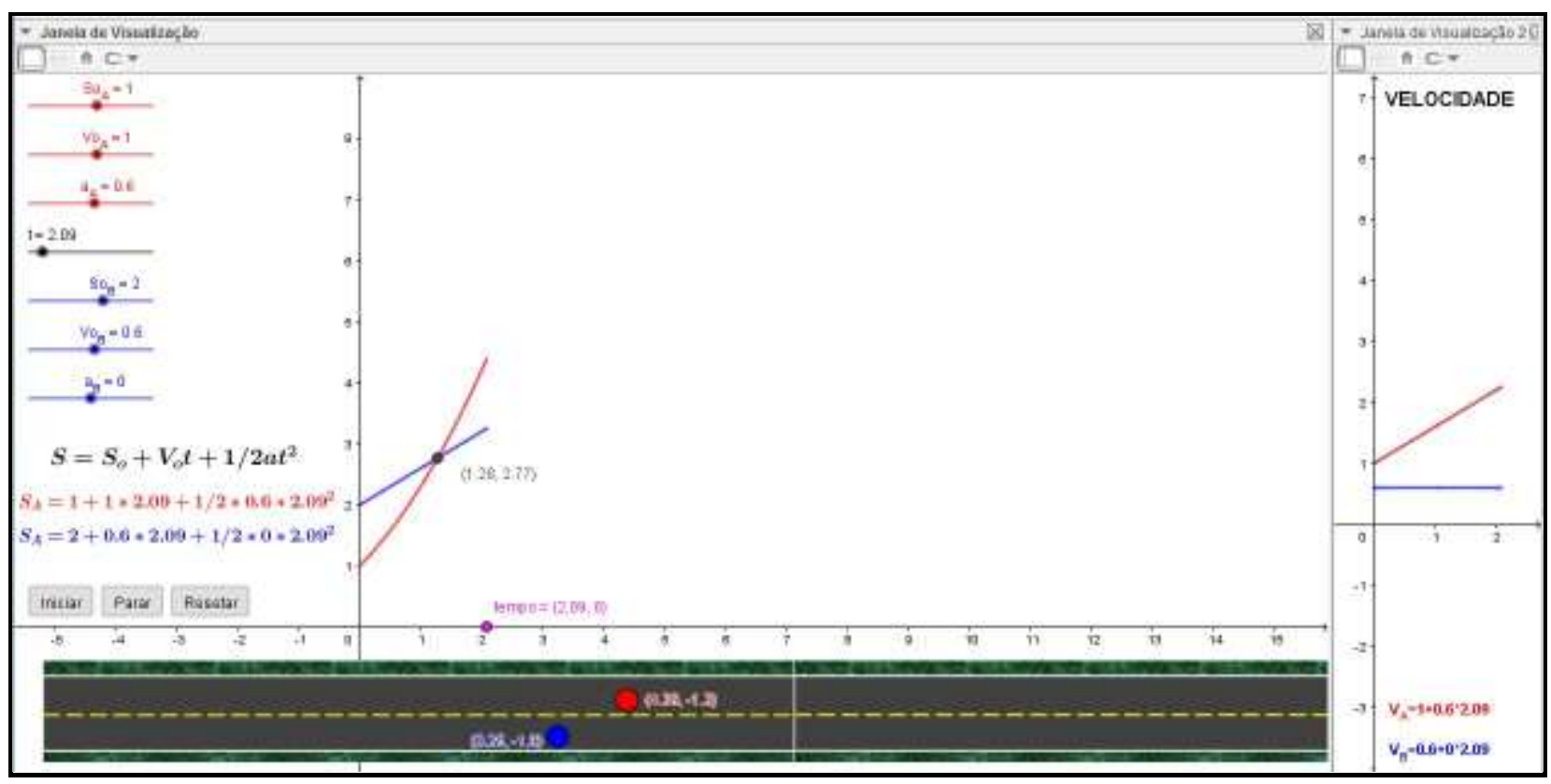

Figura 6 - Aplicativo construído no GeoGebra para o estudo da Cinemática

\subsection{Avaliação imediata}

Com o objetivo de verificar o grau de aprendizagem em relação ao conteúdo apresentado, foi aplicado um questionário (apresentado a seguir) ligado aos conceitos fundamentais das funções afins e quadráticas.

O mesmo questionário avaliativo foi aplicado em três aulas distintas. Inicialmente, na sequência da aula tradicional e, num segundo momento, após a nova abordagem do assunto com auxílio do GeoGebra. Foram realizados dois tipos de mensuração, a quantificação de acertos e erros, item por item, levando em consideração a utilização ou não do software, e, dentre as questões respondidas com correção, os itens foram comparados entre si, e foi possível verificar se houve maior lucidez, ou não, entre os acertos com e sem o GeoGebra. Numa terceira aula, foi solicitado aos alunos que refizessem os itens que eles haviam errado na primeira tentativa, porém, com o auxílio dos aplicativos produzidos no GeoGebra (Figuras 5 e 6).

\section{AVALIAÇÃO IMEDIATA}

1) Dada a função afim $f(x)=a x+2$, o que ocorrerá com o gráfico ao alterar o valor do coeficiente angular "a" Construa o gráfico das funções abaixo, e responda:

a)

\begin{tabular}{|c|l|}
\hline Coeficiente angular “a” & $\begin{array}{l}\text { Olhando da esquerda para a direita, a reta apresentada no } \\
\text { plano cartesiano será crescente, decrescente ou constante? }\end{array}$ \\
\hline$a=5$ & \\
\hline$a=2$ & \\
\hline$a=0$ & \\
\hline$a=-2$ & \\
\hline$a=-5$ & \\
\hline
\end{tabular}


b) O que ocorrerá quando admitimos valores positivos para o coeficiente " $a$ ", ou seja, $a>$ 0 ? E quando admitimos valores negativos para o coeficiente " $a$ ", ou seja, $a<0$ ?

c) O que ocorrerá quando o coeficiente admitir valor igual à zero, ou seja, $a=0$ ?

d) Com base nas questões anteriores é possível estabelecer uma relação entre a variação do coeficiente com a posição da reta no plano cartesiano?

2) Dada a função afim $f(x)=2 x+b$, construa o gráfico das funções abaixo, e responda:

\begin{tabular}{|c|}
\hline Coeficiente linear “b” \\
\hline$b=4$ \\
\hline$b=2$ \\
\hline$b=-2$ \\
\hline$b=-4$ \\
\hline
\end{tabular}

a) O que ocorrerá com o gráfico da função após alterar o valor do coeficiente linear " $b$ "? Ocorrerá alguma alteração no seu coeficiente angular " $a$ "?

b) O que teremos em comum entre o "ponto de corte" da reta do gráfico com o eixo das ordenadas $(y)$ e o coeficiente linear de cada função?

3) Dada a função quadrática $f(x)=a x^{2}$, o que ocorrerá com o gráfico ao alterar o valor do coeficiente " $a$ " Construa o gráfico das funções abaixo, e responda:

a)

\begin{tabular}{|c|c|}
\hline Coeficiente angular "a" & $\begin{array}{l}\text { O que ocorreu com a curva ao variar os valores do } \\
\text { coeficiente "a" seguindo a sequência proposta na } 1 \text { a } \\
\text { coluna? }\end{array}$ \\
\hline$a=1$ & \\
\hline$a=3$ & \\
\hline$a=5$ & \\
\hline$a=0$ & \\
\hline$a=-1$ & \\
\hline$a=-3$ & \\
\hline$a=-5$ & \\
\hline
\end{tabular}

b) O que ocorrerá com a concavidade da função quando admitimos valores positivos para o coeficiente " $a$ ", ou seja, $a>0$ ?

c) O que ocorrerá com a concavidade da função quando admitimos valores negativos para o coeficiente " $a$ ", ou seja, $a<0$ ?

d) O que ocorrerá quando o coeficiente admitir valor igual à zero, ou seja, $a=0$ ?

e) Com base nas questões anteriores é possível estabelecer uma relação entre a variação do coeficiente com a posição da concavidade da curva?

4) Dada a função afim $f(x)=2 x^{2}+c$, construa o gráfico das funções abaixo, e responda: 


\begin{tabular}{|c|}
\hline Coeficiente linear " $\mathrm{c}$ " \\
\hline$c=4$ \\
\hline$c=0$ \\
\hline$c=-4$ \\
\hline
\end{tabular}

O que ocorrerá com o gráfico da função após alterar o valor do coeficiente "c"?

5) Dada a função quadrática $f(x)=x^{2}-6 x+5$ :

a) Encontre $x_{1}$ e $x_{2}, t . q . f(x)=0$.

b) Determine o valor de $f(x)$ para:

\begin{tabular}{|l|l|}
\hline$\frac{x_{1}+x_{2}}{2}-1$ & \\
\hline$\frac{x_{1}+x_{2}}{2}$ & \\
\hline$\frac{x_{1}+x_{2}}{2}+1$ & \\
\hline
\end{tabular}

\subsection{Teste Neurolinguístico}

Um dos objetivos do estudo foi verificar se ferramentas tecnológicas, como o GeoGebra, favorecem algum grupo específico de alunos, desse modo, a fim de classificar o universo dos 30 alunos quanto aos seus Sistemas Representacionais Preferenciais, foi aplicado um Teste Neurolinguístico, que indicava como o aluno comunica-se melhor (canal visual, auditivo ou cinestésico) (Teste Neurolinguístico, 2018).

\section{RESULTADOS E DISCUSSÕES}

Os gráficos seguintes (Figura 7 a Figura 11) quantificam e comparam os resultados da avaliação aplicada, levando em consideração os dois momentos distintos da análise, inicialmente, sem o auxílio do GeoGebra, e, posteriormente, com a utilização do software. Pode-se observar uma melhora de desempenho considerando as respostas totalmente ou parcialmente corretas. 


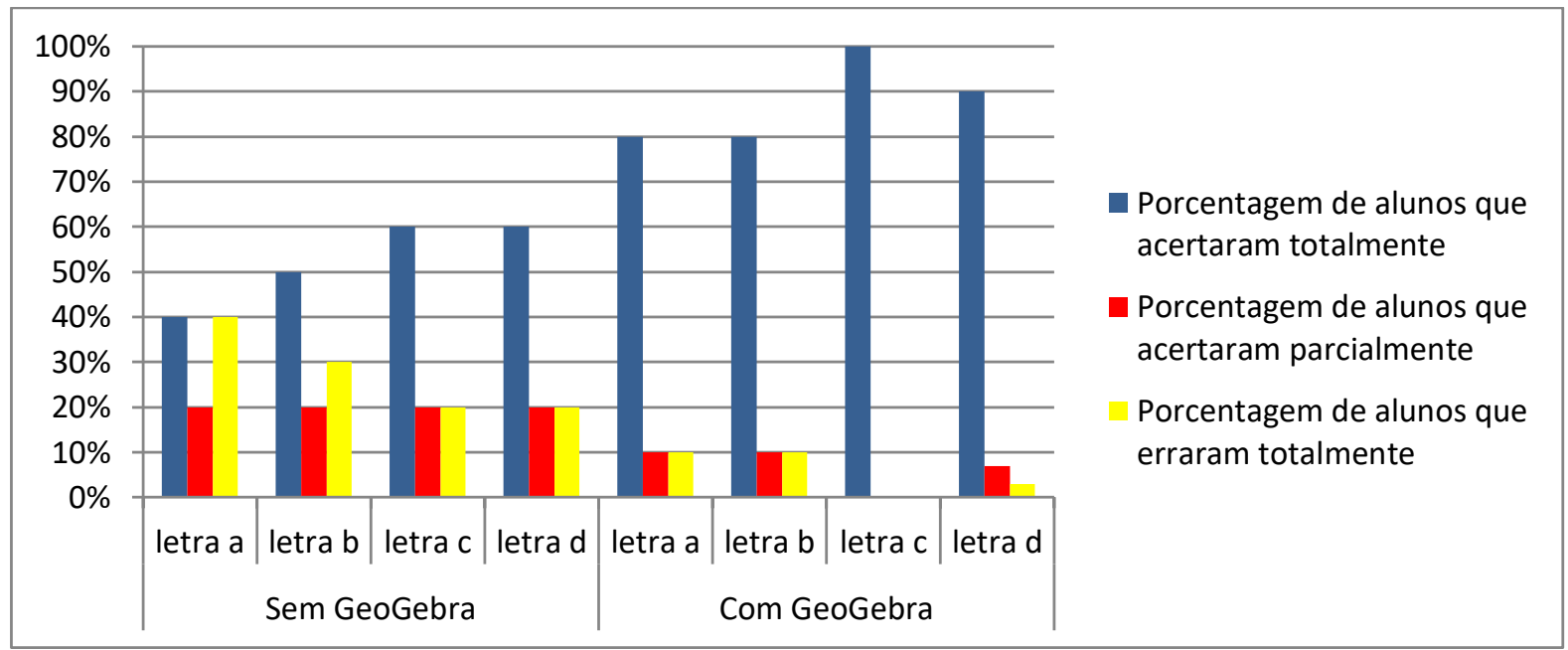

Figura 7 - Gráfico: Resultados obtidos no item 1 da avaliação

Na Figura 7 é possível observar que o auxílio da ferramenta GeoGebra contribuiu para que houvesse um melhor entendimento à respeito da representação gráfica da função afim e suas alterações, a medida em que o coeficiente " $a$ " assumia valores negativos, nulo ou positivos.

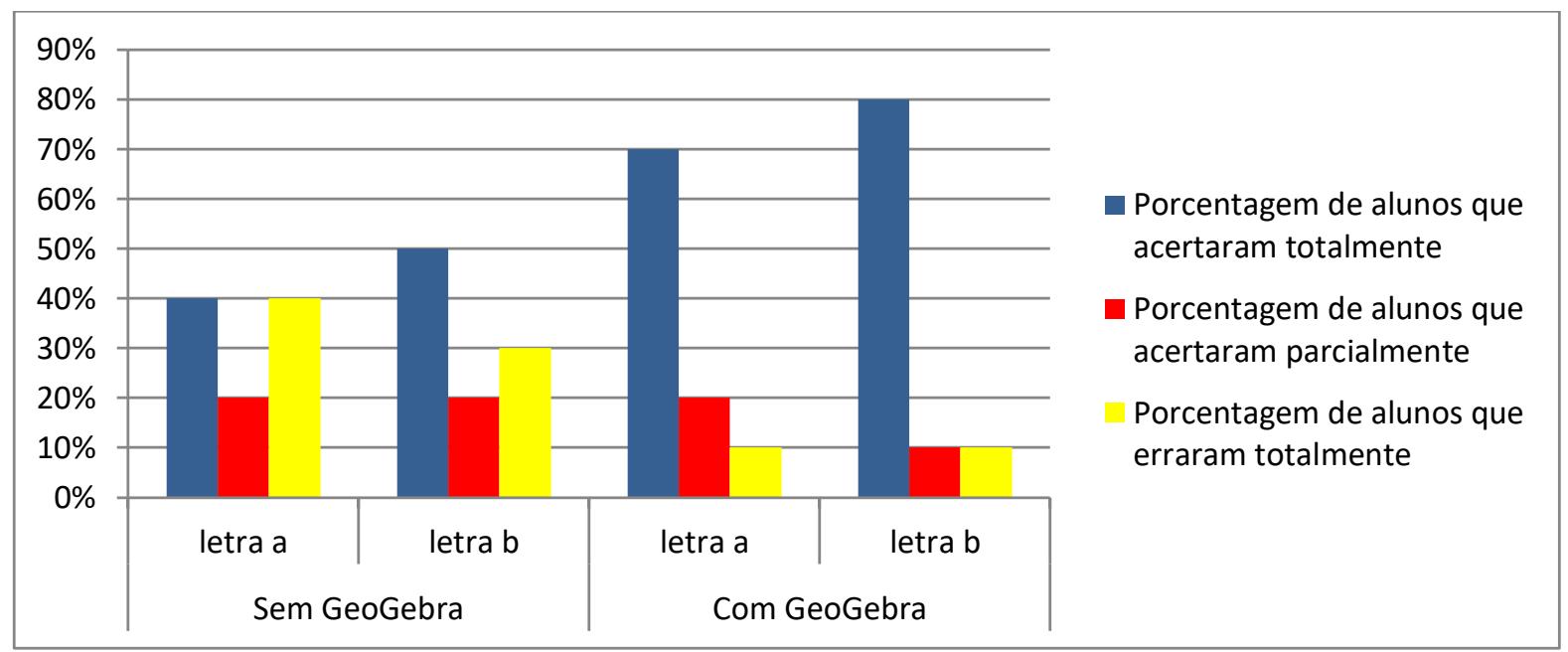

Figura 8 - Gráfico: Resultados obtidos no item 2 da avaliação

A Figura 8 representa a compilação das respostas do item 2 da avaliação aplicada, e, conforme mostra o gráfico, com a utilização do GeoGebra, houve uma melhora de aproximadamente $30 \%$ no entendimento do que pode ocorrer com a representação gráfica da função afim conforme o coeficiente linear varia entre $b<0$ e $b>0$. 


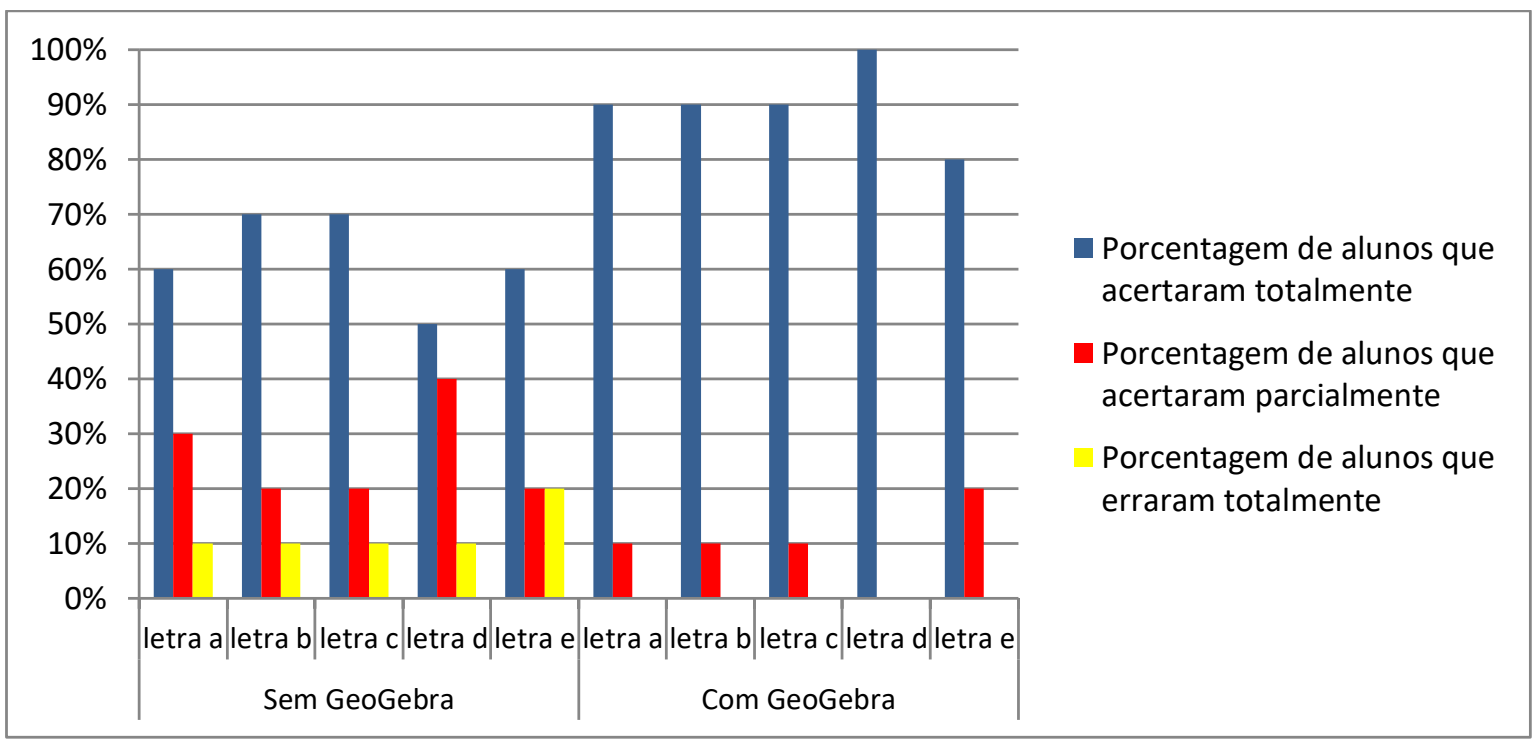

Figura 9 - Gráfico: Resultados obtidos no item 3 da avaliação

Na Figura 9 é possível verificar que há uma diferença marcante de rendimento entre as respostas fornecidas nas avaliações aplicadas com e sem a utilização do GeoGebra durante a aula introdutória do assunto função quadrática.

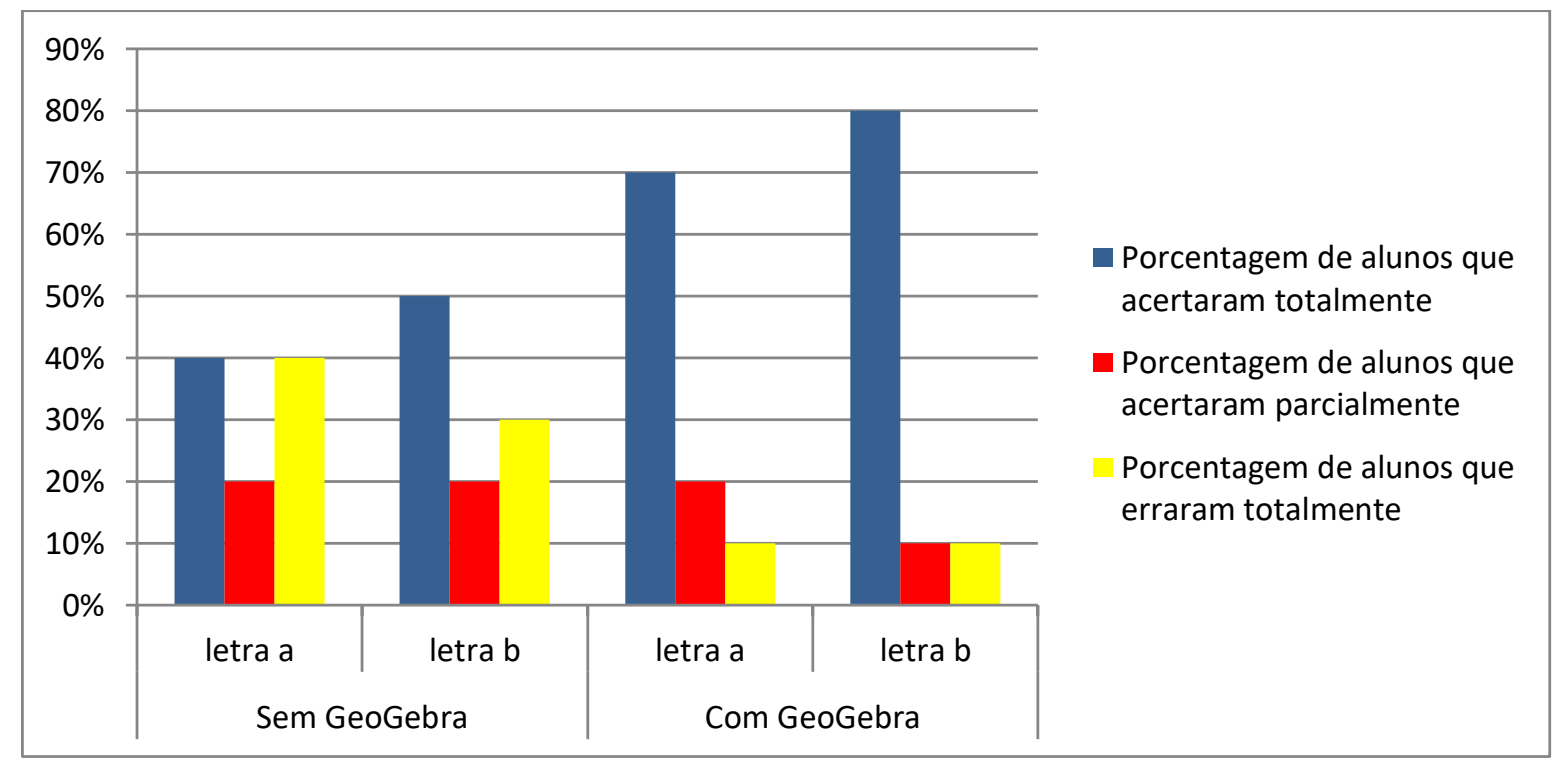

Figura 10 - Gráfico: Resultados obtidos no item 4 da avaliação

A Figura 10 concatena as respostas apresentadas pelos alunos nas avaliações apresentadas no primeiro e segundo encontros, nas quais os alunos foram questionados sobre a alteração gráfica ocorrida na função quadrática conforme o coeficiente "c" assumia os valores $-4,0$ e 4 . O que se pode inferir é que a utilização da ferramenta digital, em termos quantitativos, contribui para a melhora no rendimento dos discentes. 


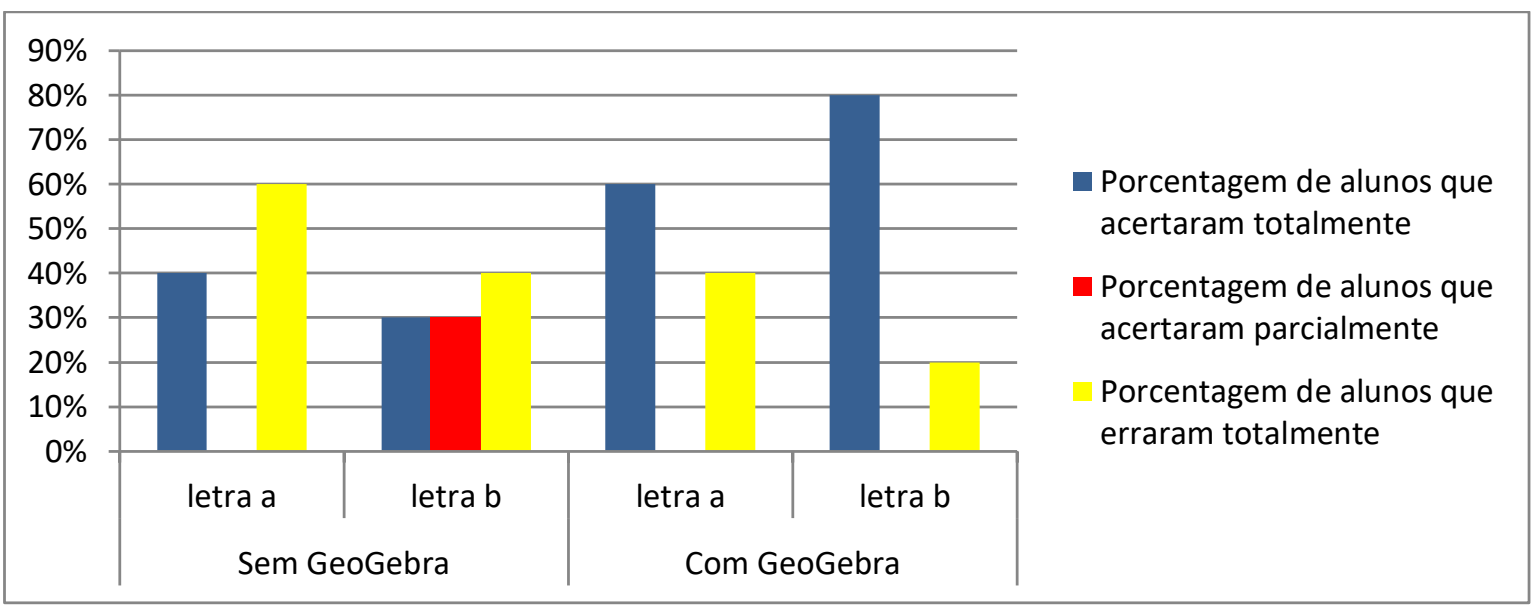

Figura 11 - Gráfico: Resultados obtidos no item 5 da avaliação

No item 5 da avaliação aplicada, o auxílio visual do software GeoGebra contribuiu de tal maneira, que a diferença de rendimento na letra $b$ deste item foi de $50 \%$ (Gráfico 5).

Ao analisar os dados nas Figuras 7 a 11, observou-se que o índice de acertos na sequência da aula ministrada com apoio do GeoGebra superou a aula tradicional em aproximadamente $30 \%$, e, ao verificar as repostas das avaliações, em quase $70 \%$ das assertivas, o grau de detalhamento das respostas foi maior que na primeira tentativa.

A seguir, serão apresentados alguns recortes das respostas descritas nas avaliações aplicadas com a utilização do GeoGebra (Figuras 12 a 21).

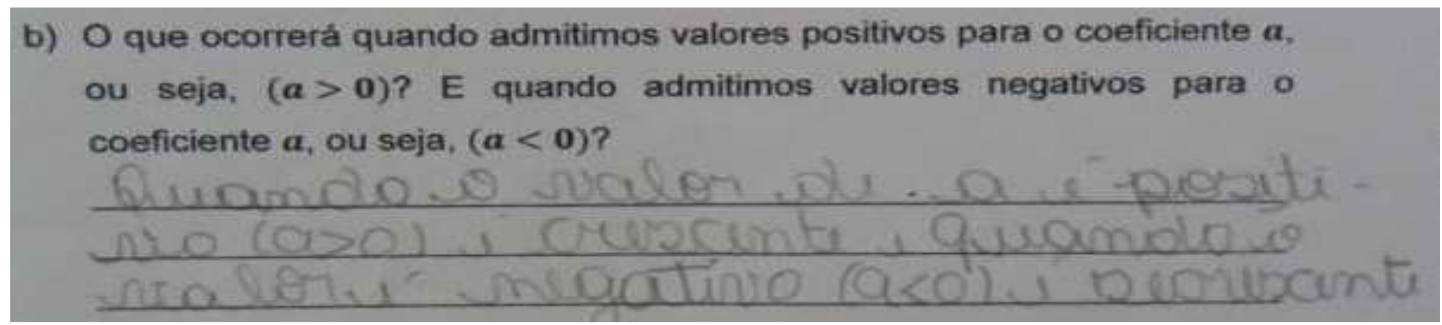

Figura 12 - Recorte de uma resposta da letra b) do item 1

No exemplo acima (Figura 12) pode-se observar que o(a) aluno(a) compreendeu a relação de variação do valor no coeficiente em relação à posição da reta no gráfico.

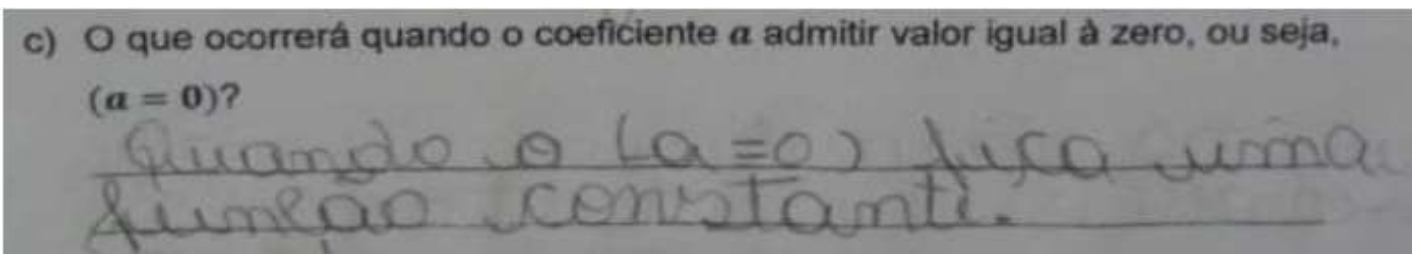

Figura 13 - Recorte de uma resposta da letra c) do item 1 
Neste caso (Figura 13), nota-se que o(a) aluno(a) conseguiu identificar corretamente o que ocorre com o gráfico de uma função afim quando o coeficiente assume valor igual a zero, apresentando uma resposta direta.

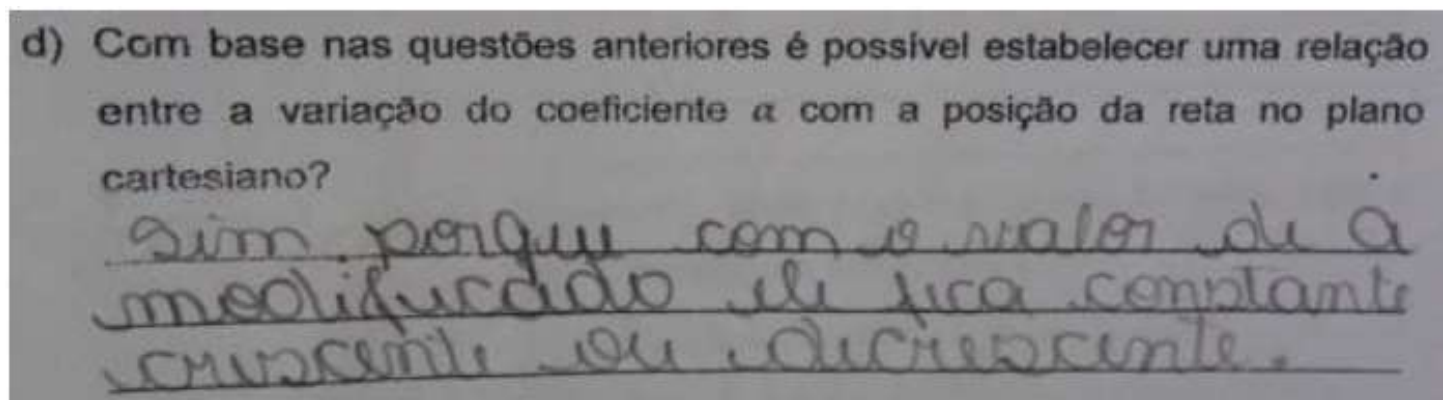

Figura 14 - Recorte de uma resposta da letra d) do item 1

Na Figura 14, é possível observar uma resposta na qual o(a) aluno(a) demonstra compreensão na relação de variação do coeficiente quanto à posição crescente, decrescente e constante da reta no plano cartesiano, apresentando a formação do conceito esperado.

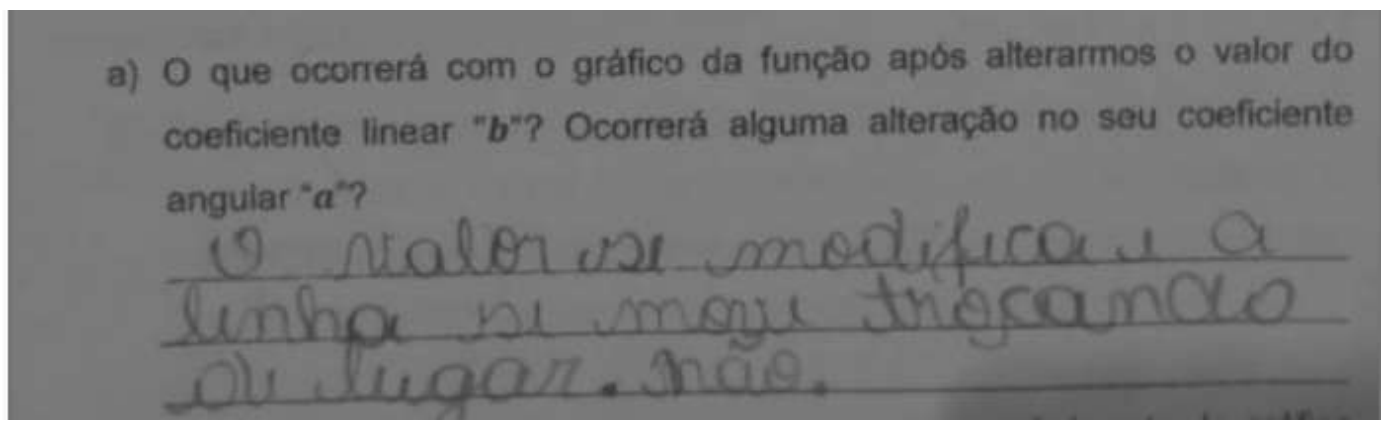

Figura 15 - Recorte de uma resposta da letra a) do item 2

Na Figura 15, pode-se ver que o(a) aluno(a) apresenta uma resposta condizente, mostrando que compreendeu o que ocorre no gráfico de uma função afim ao se alterar o valor do coeficiente " $b$ ".

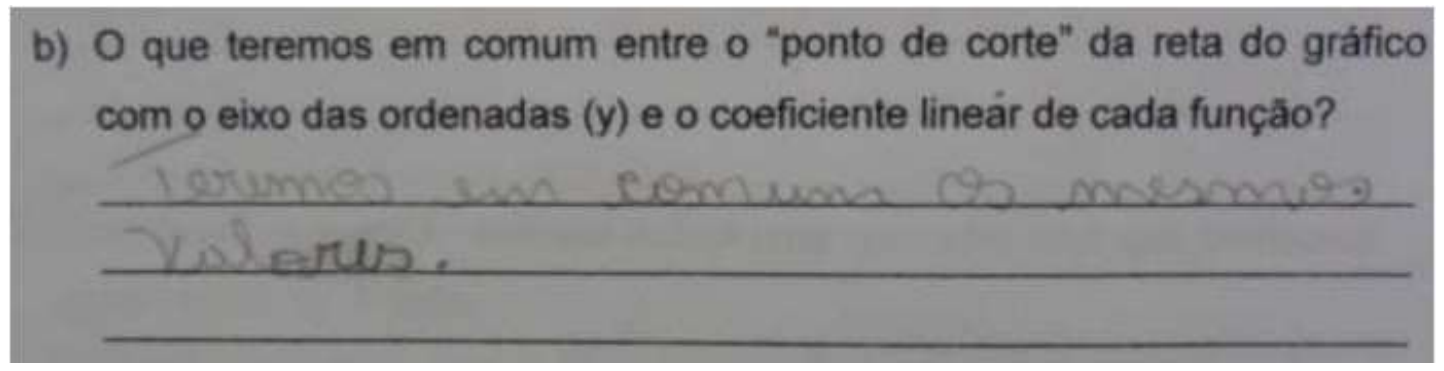

Figura 16 - Recorte de uma resposta da letra b) do item 2

Neste caso (Figura 16), observa-se uma resposta clara, direta e objetiva, mostrando o entendimento desejado com relação ao questionamento feito. 


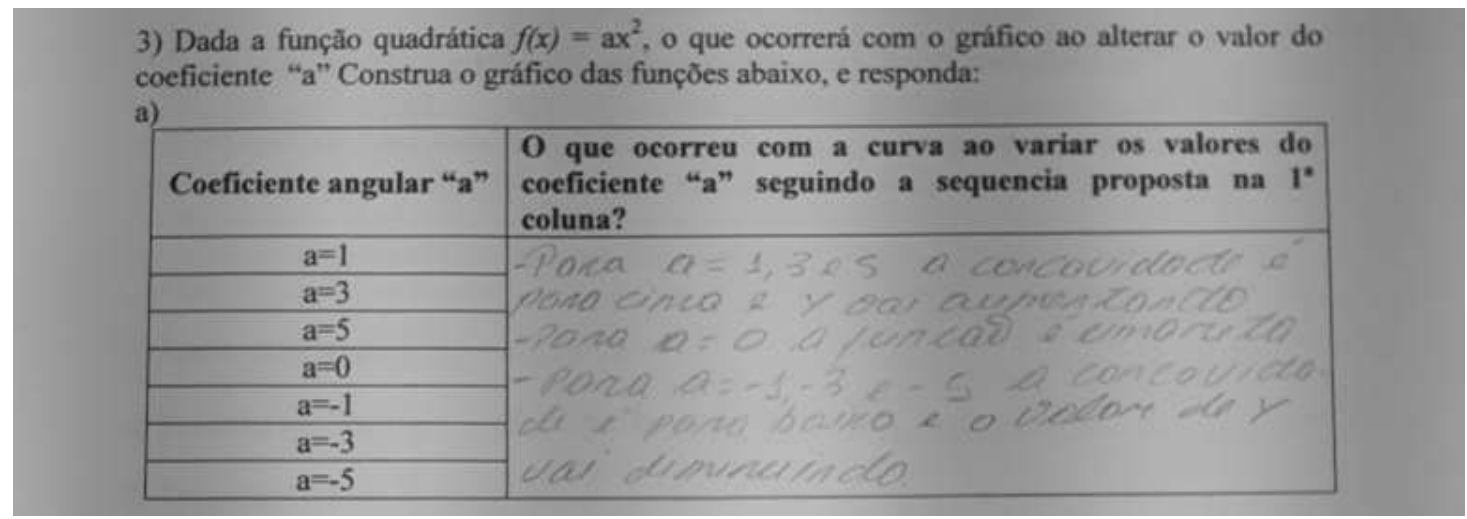

Figura 17 - Recorte de uma resposta da letra a) do item 3

Na Figura 17, o(a) aluno(a) percebeu que o efeito do parâmetro " $a$ " é aumentar ou diminuir o valor da função, conforme $a>0$ ou $a<0$, e que o gráfico tem concavidade para cima ou para baixo, conforme $a>0$ ou $a<0$, respectivamente, e que no caso de $a=0$, a função é uma constante coincidente com o eixo das abscissas.

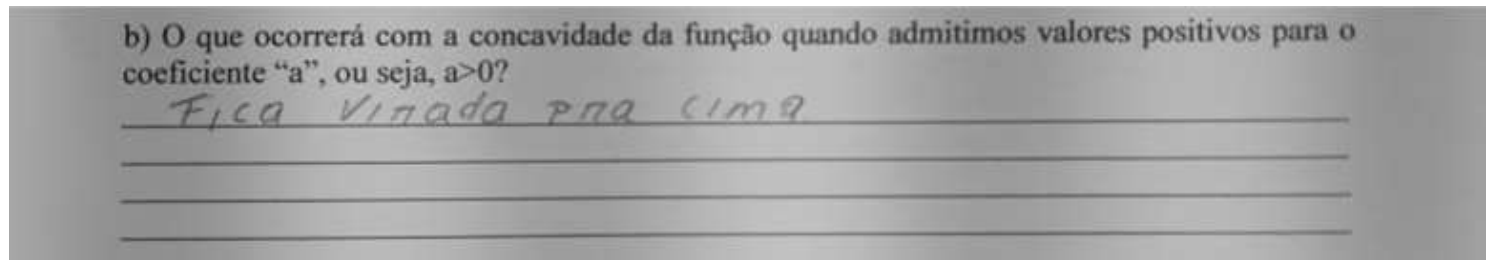

Figura 18 - Recorte de uma resposta da letra b) do item 3

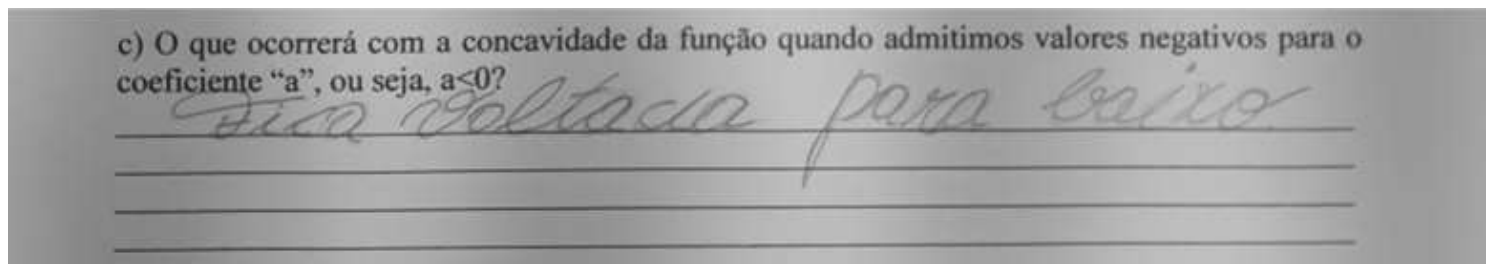

Figura 19 - Recorte de uma resposta da letra c) do item 3

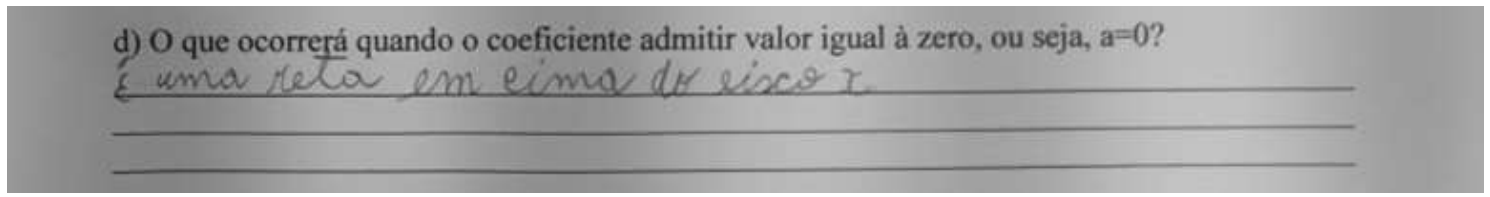

Figura 20 - Recorte de uma resposta da letra d) do item 3)

As Figuras 18, 19 e 20 exemplificam casos em que os(as) alunos(as) demonstraram o correto entendimento a respeito dos efeitos provocados no sentido da concavidade, de acordo com a variação no valor do parâmetro " $a$ ". A percepção da mudança no sentido da concavidade, em virtude da alteração do coeficiente " $a$ ", é facilitado pela característica que o GeoGebra possui de aliar a representação visual da função à sua construção algébrica. 
4) Dada a função afim $f(x)=2 x^{2}+c$, construa o gráfico das funções abaixo, e responda:

\begin{tabular}{|c|}
\hline Coeficiente linear " $\mathrm{c}$ " \\
\hline $\mathrm{c}=4$ \\
\hline $\mathrm{c}=0$ \\
\hline $\mathrm{c}=-4$ \\
\hline
\end{tabular}

a) O que ocorrerá com o gráfico da função após alterar o valor do coeficiente "c"?

moretsats

Figura 21 - Recorte de uma resposta da letra a) do item 4

Na Figura 21 está uma resposta na qual o(a) aluno(a) percebeu que o efeito do parâmetro " $c$ " é deslocar o gráfico verticalmente. $O$ deslocamento é para cima se " $c$ " cresce e para baixo se " $c$ " decresce. Isso vale tanto para os casos em que $a>0$ quanto para os casos com $a<0$.

Outra mensuração que merece destaque é o índice de acertos durante a avaliação oral realizada entre os alunos que erraram algum dos itens na primeira avaliação (sem auxílio do GeoGebra). Quando autorizados a utilizar o aplicativo, que simula as alterações gráficas da função conforme se modificam os parâmetros, esse índice foi de $100 \%$, ou seja, com a possibilidade de manipular o aplicativo, e alterar aleatoriamente os parâmetros, os alunos conseguiram perceber, sem qualquer dificuldade, as consequências produzidas nos gráficos em virtude das alterações nos coeficientes das funções afim e quadrática.

De modo geral, o que pode ser observado, verificando os dados compilados nos gráficos e o resultado do teste neurolinguístico, é que os alunos que apresentaram melhora nas avaliações com a utilização do GeoGebra possuíam, em sua maioria, como sistema preferencial, os canais visuais e/ou cinestésicos, o que justifica o melhor desempenho obtido após o suporte fornecido pelo software.

Algumas expressões voluntárias merecem serem citadas, como por exemplo, quando um aluno se manifestou durante a aula afirmando "Agora sim, faz sentido!" ou "Isso sim é aula de matemática!". Manifestações como essas reforçam o que diz Moran (2007), afirmando que alunos sem acesso às redes digitais são alunos excluídos de parte importante da aprendizagem atual. Essa opinião também é reforçada por Rodrigues (2014), defendendo que a utilização do computador tem se mostrado um elo entre a teoria e a prática, e que seu emprego tende a construir um ambiente marcado por uma maior proximidade, interação e colaboração.

Quando abordados os tópicos referentes à Física, a simulação dos dois objetos se movimentando simultaneamente, e os respectivos gráficos das funções, também facilitou, segundo relatos dos alunos, a visualização e compreensão do comportamento dos dois corpos, um em relação ao outro.

\section{CONCLUSÕES}

O objetivo inicial deste estudo foi plenamente atendido ao longo da pesquisa, ao discutir o GeoGebra como opção de ferramenta tecnológica capaz de tornar a aula de matemática mais 
atrativa, dinâmica, interativa, assíncrona, e capaz de atender de maneira eficiente a heterogeneidade presente na maioria das salas de aula do ensino brasileiro.

O que pode ser observado acerca dos dados coletados durante o estudo das funções afim e quadrática, também conhecidas como funções polinomiais do 1 e e 20 grau, respectivamente, é que o fato do aluno poder visualizar a materialização dos seus cálculos na tela, do computador ou celular, lhe traz mais credibilidade a respeito do que, até então, não passava de um conhecimento abstrato.

A parte do estudo que mais chamou atenção, em virtude das expressões de surpresa dos alunos, foi o momento das simulações de movimentos relativos entre dois objetos, com auxílio do GeoGebra, durante a discussão do comportamento das funções no estudo de MRU e MRUV.

Outro aspecto relevante observado entre o segundo e terceiro encontros foi o fato de que alguns alunos, mesmo sem terem sido incentivados a isso, visitaram o endereço eletrônico onde os aplicativos foram hospedados e relataram experiências extraclasse, no sentido de praticar e tirar dúvidas sobre o assunto ministrado em sala de aula, demonstrando, dessa forma, a capacidade de ferramentas como o GeoGebra de possibilitarem que o processo de aprendizagem transponha os muros da escola.

O GeoGebra também se mostrou diferenciado, pois funciona em múltiplas plataformas, possibilitando que o aluno tenha acesso ao software em aparelhos como smartphones, tablets e notebooks. Os arquivos construídos no GeoGebra viram "aplicativos" que podem rodar localmente, nos aparelhos onde foram produzidos, ou podem ser hospedados em um endereço online, fornecido pelo desenvolvedor do GeoGebra, e compartilhados gratuitamente através da internet, facilitando seu acesso online por diversos usuários.

\section{REFERÊNCIAS}

Almeida Filho, N (1997). Transdisciplinaridade e Saúde Coletiva. Ciência \& Saúde Coletiva, 2(1-2), 5-20. https://doi.org/10.1590/1413-812319972101702014.

Alonso, C., Gallego, D., \& Honey, P. (2002). Los estilos de aprendizaje: procedimientos de diagnóstico y mejora. Madrid: Mensajero,

Antunes, C. (2007). Novas maneiras de ensinar novas formas de aprender. 1. ed. Porto Alegre, RS: Artmed.

Borba, M. C. (2018). Softwares e internet na sala de aula de matemática. Recuperado a partir de: http://igce.rc.unesp.br/\#!/pesquisa/gpimem---pesq-em-informatica-outras-midias-eeducacao-matematica/downloads/artigos-para-download/.

Comitê Gestor da Internet no Brasil. (2016). Pesquisa sobre o uso das tecnologias de informação e comunicação nas escolas brasileiras: TIC educação 2015. Núcleo de Informação e Coordenação do Ponto BR, (editor). São Paulo. Recuperado a partir de: https://www.cetic.br/media/docs/publicacoes/2/TIC Edu 2015 LIVRO ELETRONICO.pdf.

Dante, L. R. (2008). Matemática. São Paulo, SP: Ática. 
Diretrizes curriculares nacionais para o ensino médio. (1999). Parâmetros Curriculares Nacionais Ensino Médio, Volume 1. Brasília: Ministério da Educação, Secretaria da Educação Média e Tecnológica.

Ferri, J., Schimiguel, J., \& Calejon, L. M. C. (2013). Uso do GeoGebra no Ensino de Matemática. Recuperado a partir de: http://www.gestaouniversitaria.com.br/artigos/uso-do-geogebrano-ensino-de-matematica--2.

Lévy, P. (1993). As Tecnologias da Inteligência: o futuro do pensamento na era da informática. Tradução: Carlos Irineu da Costa. São Paulo: Editora 34.

Lima, E. L., Carvalho, P. C. P., Wagner, E., \& Morgado, A. C. (2006) A matemática do ensino médio. v. 1. 9 ed. Rio de Janeiro: SBM.

López, J. M. B. \& Velásques, F. R. Los estilos de aprendizaje y el locus de control en estudiantes que inician estudios superiores y su vinculación con el rendimiento académico. Recuperado a partir de: http://www.redalyc.org/articulo.oa?id=65811489010.

Lopez, R. B. \& Tosina, R. Y. (2011). Digiculturalidad.com. Interculturalidad y TIC unidas em el desarrollo del enfoque competencial del curriculum. In: Leiva, J. \& Borrero, R. (Coord.). Interculturalidad y escuela. Perspectivas pedagógicas en la construcción comunitaria de la escuela intercultural. Barcelona: Octaedro. 145-164.

Mojica, D. C. (2004). Enseñanza y aprendizaje en la educación superior: Un reto para el siglo XXI. Universidad de Puerto Rico. Recuperado a partir de: http://pepsic.bvsalud.org/scielo.php?script=sci nlinks\&ref=2641781\&pid=S1665$\underline{7527200800010000500006 \& \operatorname{lng}=\mathrm{es} \text {. }}$

Montgomery, S. (1995). Addressing Diverse Learning Styles Through the Use of Multimedia. In: 25 Annual Conference. Engineering Education for the 21st Century, Atlanta, GA, USA Recuperado a partir de: https://ieeexplore.ieee.org/abstract/document/483093/.

Moran, J. M. (2007). A educação que desejamos: novos desafios e como chegar lá. 2. ed. Campinas, SP: Papirus.

Rodrigues, P. M. S. (2014). Metodologia do ensino da matemática frente ao paradigma das novas tecnologias de informação e comunicação: A internet como recurso no ensino da matemática. 1. ed. Duque de Caxias, RJ: Espaço Científico Livre Projetos Editoriais.

Soares, J. H. S. (2013). Função Quadrática. (Dissertação de mestrado, Universidade Federal do Rio Grande do Norte, Natal, Mestrado Profissional em Matemática em Rede Nacional - PROFMAT).

Teste Neurolinguístico (2018). Teste e Exercícios sobre Sistemas Representacionais. Recuperado a partir de: https://golfinho.com.br/teste-e-exercicios-sobre-sistemas-representacionaisvac.htm. 


\section{COMO CITAR ESTE ARTIGO:}

Feitoza W. G., Medeiros E. J. R., Medeiros S. R. R., Medeiros JR R. N., Lourenço E. G. (2020). Geogebra: Recurso Visual e Cinestésico no Ensino de Funções. Holos.36(5), 1-23.

\section{SOBRE OS AUTORES}

\section{W. G. FEITOZA}

Possui graduação em Matemática pela Universidade Tuiuti do Paraná (2003), Especialização nas áreas de Ensino de Matemática para o Ensino Médio (2018), Metodologia do Ensino de Matemática e Física (2012) e Gestão Escolar - Direção, Orientação e Supervisão (2004). Possui experiência no Ensino de Matemática e Física no Ensino Fundamental e Médio, cursos preparatórios pré-vestibular, sistema EJA e na área de Matemática com ênfase em informática. Atualmente é professor do Colégio Militar de Recife e participa como membro do Núcleo Multidisciplinar de Ensino, Engenharia e Ciências (NuMEEC) E-mail: weddington.feitoza@academico.ifrn.edu.br

ORCID ID: https://orcid.org/0000-0001-9731-5794

\section{E. J. R. MEDEIROS}

Graduado (2006) em Matemática pela Universidade Federal do Rio Grande do Norte - UFRN. Graduando em Ciências e Tecnologia pela Universidade Federal do Rio Grande do Norte - UFRN. Especialista (2011) em Gestão e Organização Escolar pela Universidade Potiguar - UnP. Mestre (2008) e Doutor (2012) em Ciência e Engenharia de Petróleo pela Universidade Federal do Rio Grande do Norte - UFRN (2008). Atualmente, Professor do Instituto Federal do Rio Grande do Norte - IFRN e Coordenador do Núcleo Multidisciplinar de Ensino, Engenharia e Ciências (NuMEEC). Tem experiência/interesse nas áreas de Matemática, Ensino de Ciências, Tecnologias Digitais, Energias e Engenharia de Petróleo. E-mail: elthon.medeirosl@ifrn.edu.br ORCID ID: https://orcid.org/0000-0002-5187-0992

\section{S. R. R. MEDEIROS}

É professora do Instituto Federal de Educação, Ciência e Tecnologia do Rio Grande do Norte (IFRN) - Campus João Câmara e Campus Zona Leste. Tem experiência nas áreas de Saúde Coletiva, Segurança do Trabalho, Metodologia Científica e Ensino de Ciências. Atualmente participa como membro do Núcleo Multidisciplinar de Ensino, Engenharia e Ciências (NuMEEC). E-mail: stella.medeiros@ifrn.edu.br

ORCID ID: https://orcid.org/0000-0003-0869-9111

\section{R. N. MEDEIROS JR}

Possui Licenciatura em Física, Especialização em Gestão e Organização Escolar e Mestrado em Engenharia de Petróleo e Gás, hodiernamente é doutorando em Ciência e Engenharia de Petróleo. Tem experiência nas áreas de Formação Docente, Experimentação e Tecnologias Aplicadas ao Ensino de Física, Ciência e Engenharia de Petróleo e Gás. Foi tutor do Programa de Educação Tutorial - PET da Licenciatura em Física do Instituto Federal de Educação, Ciência e Tecnologia do Rio Grande do Norte (IFRN) - Campus João Câmara, onde atualmente é professor, e coordenador do grupo de pesquisa Núcleo Multidisciplinar de Ensino, Engenharia e Ciências (NuMEEC) e membro do Núcleo Multidisciplinar de Ensino, Engenharia e Ciências, e do Núcleo de Pesquisa em Formação Docente e Ensino de Física. E-mail: nonato.junior@ifrn.edu.br

ORCID ID: https://orcid.org/0000-0003-2580-0795

\section{E. G. LOURENÇO}

Possui graduação em Licenciatura em Matemática pela Universidade Federal do Rio Grande do Norte (2008) e Mestrado em Matemática pela UFERSA (2013). Atualmente é professor do Instituto Federal de Educação, Ciência e Tecnologia do Rio Grande do Norte e membro do Núcleo Multidisciplinar de Ensino, Engenharia e Ciências (NuMEEC).E-mail: emanuel.lourenco@ifrn.edu.br

ORCID ID: https://orcid.org/0000-0002-4233-4469 
Editor(a) Responsável: Francinaide de Lima Silva Nascimento

Pareceristas Ad Hoc: Arivonaldo da Silva e Jose Silva

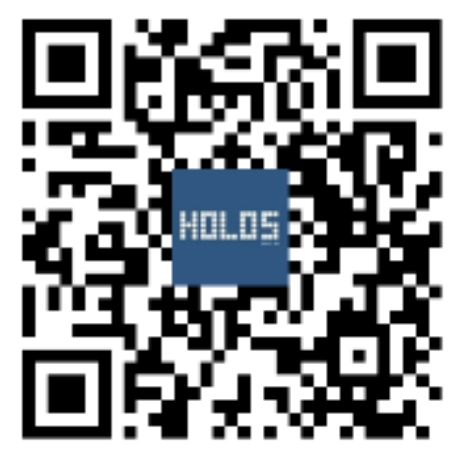

